\title{
SABERES TRADICIONAIS: PROCESSO DE ENSINO E APRENDIZAGEM DOS EMPREENDEDORES DA COOPERATIVA DE ETNODESENVOLVIMENTO KITAANDA BANTU
}

\author{
TRADITIONAL KNOWLEDGE: TEACHING AND LEARNING \\ PROCESS OF KITAANDA BANTU ETHNODESPROVEMENT \\ COOPERATIVE ENTREPRENEURS \\ CONOCIMIENTOS TRADICIONALES: PROCESO DE \\ ENSEÑANZA Y APRENDIZAJE DE LA COOPERATIVA DE \\ EMPRENDEDORES ETNODESARROLLO KITAANDA BANTU
}

\author{
Dandara Lopes Correia ${ }^{1}$
}

\section{RESUMO}

As transformações sociais e econômicas, no Brasil, na contemporaneidade vêm contribuindo para fomentar o interesse pelo empreendedorismo, mas observa-se que a maior parte dos grupos produtivos formados por povos e comunidades tradicionais vivencia falta de acesso às políticas públicas específicas que promovam a inclusão produtiva e a valorização das culturas locais. O objetivo principal deste artigo é descrever o processo de ensino e aprendizagem da Cooperativa de Etnodesenvolvimento Kitaanda Bantu, identificando os ensinamentos sobre empreendedorismo e as implicações para os empreendedores que trabalham com artesanato, gastronomia, extrativismo, agricultura familiar agroecológica e orgânica e formação cultural nessa cooperativa. Para tal, fez-se necessária a pesquisa exploratória com levantamento de dados primários e secundários, de natureza qualitativa, que proporcionou analisar a importância da educação informal no processo de ensino e aprendizagem. Este artigo proporciona impacto importante sobre o desenvolvimento de práticas, contribuindo para o fortalecimento do empreendedorismo na cooperativa, contribuindo para o desenvolvimento local sustentável.

\footnotetext{
1 Coordenadora na Coordenação de Políticas para Povos e Comunidades Tradicionais da Secretaria de Promoção da Igualdade Racial do Estado da Bahia - SEPROMI, Coordenadora de Comunicação e Marketing na Rede Mundial de Empreendedores Étnicos - EMUNDE e Coordena o Comitê Gestor da Política de Empreendedorismo de Negros e Mulheres no Estado da Bahia. Cursa Especialização em Arte e Educação UFBA, Especialização em Docência do Ensino Superior, Pós-graduada em Comunicação Corporativa. Graduada em Comunicação e Marketing. Membro do Grupo Interdisciplinar de Pesquisa em Representações, Educação e Sustentabilidade (GIPRES) do Programa de Pós-Graduação em Educação e Contemporaneidade (PPGEDUC/UNEB); Membro do Grupo de Trabalho em Educação e Contemporaneidade sobre Etnia e Educação da Universidade Salvador (UNIFACS).
} 
Palavras-chave: Povos e comunidades tradicionais. Etnodesenvolvimento. Ensino e aprendizagem. Empreendedorismo.

\begin{abstract}
The economic and social transformations in Brazil has been contributing to encourage the interest on entrepreneurship but we can observe that most part of productive groups formed by traditional people and community experiences lack of access to the specific public politic that promote the productive inclusion and the appreciation of local culture. The main goal of this article is to describe the process of teaching and learning of the Cooperativa de Etnodesenvolvimento Kitaanda Bantu, identifying the teachings about entrepreneurship and the implication on entrepreneurs who work with handicraft, gastronomy, extrativism, agroecological family farming and organic and cultural formation in this cooperative. For this, it is needed exploratory research with primary and secundary data collection about qualitative nature that provided us to analyze the importance of informal education on the process of teaching and learning. This article provides a good impact about the development of practices, contributing to the fortification of entrepreneurship in the cooperative, contributing to the sustainable local development.
\end{abstract}

Key words: Tradicional people and communities. Ethnodevelopment. Teaching and learning. Entrepreneurship.

\title{
RESUMEN
}

Las transformaciones sociales - económicas en la contemporaneidad en Brasil ha venido contribuyendo a incrementar el interés en el emprendedores, sin embargo, la mayor parte de los grupos productivos formados por pueblos y comunidades tradicionales presentan falta de acceso a las políticas públicas específicas que promuevan la inclusión productiva y la valoración de las culturas locales. El objetivo principal de este artículo es describir el proceso de enseñanza y aprendizaje de la Cooperativa de Etno-desarollo Kitaanda Bantu, identificando las enseñanzas sobre emprendimientos y las implicaciones para los emprendedores que trabajan con artesanía, gastronomía, sector extractivo, agricultura familiar agroecológica y orgánica, y formación cultural de esa cooperativa. Para este trabajo, fué necesario realizar una investigación cualitativa, a través de datos primarios y secundarios, que facilitó analizar la importancia de la educación informal en el proceso de enseñanza y aprendizaje. Este artículo proporciona importante impacto sobre el desarrollo 
de las prácticas, contribuyendo en el fortalecimiento del emprendedor y facilitando el desarrollo local sostenible.

Palabras-clave: Pueblos y comunidades tradicionales. Etno-desarrollo. Enseñanza y aprendizaje. Emprendedores.

\section{INTRODUÇÃO}

A colonização do Brasil teve início em 1530 e foi consequência do processo da expansão marítima europeia. A estratégia utilizada pelos europeus teve como principais especificidades a exploração do território, mão-de-obra escrava (indígena e africana) e apropriação de terras indígenas. Segundo Schwarcs e Gomes (2018), a escravidão mercantil africana do período moderno foi um sistema que se enraizou cruelmente na história brasileira, e que guarda marcas profundas no nosso cotidiano.

O tema proposto neste artigo dialoga com a perspectiva de romper com os paradigmas eurocêntricos hegemônicos e tem relevância por se tratar de um público que sofre do reforço e manutenção do racismo e de práticas racistas, pois o objeto de estudo escolhido para o desenvolvimento do projeto pertence ao segmento de povos de terreiro, povos marcados por anos de exclusão socioeconômica, negação de direitos, depreciação dos valores identitários.

Esses povos representam, atualmente, a memória viva das sociedades tradicionais africanas e salvaguardam a afro descendência brasileira, seja pelo zelo e respeito pela natureza, como parte primordial de sua religiosidade, ou através do conhecimento da culinária, valores, princípios, hierarquia, línguas, estéticas e indumentárias. Atualmente, no Brasil existe uma grande diversidade racial, étnica, e por reconhecer esta diversidade, o Governo Federal institui, através do Decreto 6.040/2007, a Política Nacional de Desenvolvimento Sustentável dos Povos e Comunidades Tradicionais. A partir desta, reconhece formalmente a existência dos povos e comunidades tradicionais, definindo-os enquanto“[...] grupos culturalmente diferenciados e que se reconhecem como tais, que possuem formas próprias de organização social, que ocupam e usam territórios e recursos naturais como condição para sua reprodução cultural, social, religiosa, ancestral e econômica, utilizando conhecimentos, inovações e práticas gerados e transmitidos pela tradição", conforme preconiza o inciso I do artigo $3^{\circ}$, do referido Decreto. 
Imerso neste contexto, a Bahia, por meio do Decreto 15.634/2014, instituiu a Política Estadual para o Desenvolvimento Sustentável dos Povos e Comunidades Tradicionais, que contemplam os povos indígenas, povos de terreiro, povos ciganos, comunidades extrativistas, comunidades quilombolas, comunidades de fundo e fecho de pasto, comunidades de marisqueiras e pescadores (as) e comunidades geraizeiras.

Este artigo apresenta-se com o objetivo de descrever o processo de ensino e aprendizagem dos empreendedores da Cooperativa de Etnodesenvolvimento Kitaanda Bantu. A proposta deste projeto em analisar de que forma o processo de ensino e aprendizagem beneficia os empreendedores da Cooperativa de Etnodesenvolvimento Kitaanda Bantu, se dá pela observação que a maior parte dos grupos produtivos formados por povos e comunidades tradicionais vivenciam falta de acesso às políticas públicas específicas que promovam a efetividade da inclusão produtiva e a valorização das culturas locais, além da trajetória destes ser marcada por anos de exclusão socioeconômica e negação de direitos, decorrentes do período escravista que afetou os povos indígenas e os povos negros diretamente, que acarreta a insuficiente existência de dados abordando essa temática.

Segundo Quijano (2005), faz-se necessário o rompimento de práticas que permeiam o racismo institucional e estrutural no Brasil. Estas práticas estão enraizadas, por se constituírem a partir de um padrão de poder que se originou nas colônias e perdura até o presente momento mantendo desigualdades e identidades estigmatizadas e subalternizadas, permitindo não só uma naturalização, como um aprisionamento do corpo e da imagem do negro a uma determinada posição no sistema de estratificação social brasileiro, cujo caráter é maior do que apenas o de ser uma herança do passado colonial brasileiro, é um fenômeno retroalimentado pelas práticas cotidianas atuais.

Conforme descrito no Plano de Desenvolvimento Sustentável de Povos e Comunidades Tradicionais, os povos tradicionais possuem formas próprias de organização social, sendo que a utilização do território e recursos naturais como condição para a sua reprodução cultural, social, religiosa, ancestral e econômica, é transmitido oralmente. Diante desse contexto, faz-se necessário, o reconhecimento da contribuição desses povos na construção do Brasil e a valorização da ancestralidade que estabelece vínculos identitários entre o continente africano e o Brasil. Os territórios tradicionais dos povos de terreiro são ricos em transmissão de saberes tradicionais não formais que proporcionam a garantia da reprodução da organização social, a partir de aspectos culturais, sociais, religiosos, 
ancestrais e econômicos, que permitem a preservação do patrimônio cultural e desta forma promove o desenvolvimento sustentável desses povos. Esta educação não formal constitui um "conjunto de processos, meios, instituições, específica e diferencialmente desenhada em função de explícitos objetivos de formação e instrução que não estão dirigidos à concessão de grau, próprio do sistema educativo formal" (TRILLA, 1993, p. 30 apud CALIMAN, 2010, p. 30).

Segundo Otto (2009) a Pedagogia Social como conceito da teoria e como campo de estudo originou-se como uma crítica da Educação focada no desenvolvimento dos indivíduos sem considerar as dimensões sociais da existência humana e a educação do indivíduo se vincula a condições sociais da cultura e as condições culturais da vida social. Para Freire (2005) é a pedagogia que se caracteriza como um projeto de transformação político-social visando ao fim da exclusão e da desigualdade, voltada para as classes populares. Estes conceitos são importantes para o alcance da proposta de pesquisa, pois o processo de educação precisa conglomerar saberes da humanidade, conhecimentos técnicocientíficos, saberes tradicionais das comunidades, experiências e vivências das pessoas, não sendo uma construção engessada.

No intuito de responder ao questionamento, "de que forma o processo de ensino e aprendizagem beneficia os empreendedores da Cooperativa de Etnodesenvolvimento Kitaanda Bantu?", procurou-se realizar um estudo científico cujo objetivo principal consiste em observar o processo de ensino e aprendizagem da Cooperativa de Etnodesenvolvimento Kitaanda Bantu, identificando os ensinamentos sobre empreendedorismo e as implicações para os empreendedores que atuam na cooperativa. Como etapas para o alcance do objetivo geral, estabeleceram-se os seguintes objetivos específicos: a. Delinear o processo de formação empreendedora na Cooperativa de Etnodesenvolvimento Kitaanda Bantu; b. Contribuir para melhoria no processo de fortalecimento do empreendedorismo na Cooperativa de Etnodesenvolvimento Kitaanda Bantu; c. Descrever os fatores que interferem no desenvolvimento sustentável das comunidades que fazem parte da Rede Kitaanda Bantu.

A pesquisa tem como proposta investigar os seguintes pressupostos: que atual falta de sistematização do conhecimento dificulta o processo de ensino e aprendizagem da Cooperativa de Etnodesenvolvimento Kitaanda Bantu. A segunda proposição é a perspectiva de que o empreendedorismo fortalece o potencial produtivo da Cooperativa de 
Etnodesenvolvimento Kitaanda Bantu. Por fim, numa terceira proposição é que o trabalho na perspectiva de rede fortalece o desenvolvimento local sustentável das comunidades envolvidas.

No contexto da sociedade atual, o empreendedorismo se estabelece como fenômeno sociocultural profundamente relacionado ao processo educacional na formação de novas gerações. Assim sendo, as contribuições de Dolabela (2003) tem bastante aderência na perspectiva da prática pedagógica e do desenvolvimento local sustentável.

Educar quer dizer evoluir sem mudar as nossas raízes; pelo contrário, reconhecendo e ampliando as energias que dela emanam. É também despertar a rebeldia, a criatividade, a força da inovação para construir um mundo melhor. Mas é principalmente construir a capacidade de cooperar, de dirigir energias para a construção do coletivo. É substituir a lógica do utilitarismo e do individualismo pela construção do humano, do social, da qualidade de vida para todos (DOLABELA, 2003, p. 31).

Tendo como premissa esta afirmação, esta pesquisa se propõe a observar esses ensinamentos com a temática empreendedora para os membros que compõem a Cooperativa de Etnodesenvolvimento Kitaanda Bantu e a contribuição para o fortalecimento das ações da Cooperativa, em busca de examinar memórias, práticas tradicionais, costumes que são essenciais na prática e na trajetória das pessoas que fazem parte do grupo produtivo. Para tanto buscaremos descrever o processo de ensino e aprendizagem do grupo produtivo e identificar os fatores que interferem nas ações empreendedoras deste grupo.

A escolha do campo empírico de estudo recaiu sobre a Cooperativa de Etnodesenvolvimento Kitaanda Bantu, em razão de ser uma rede de núcleos produtivos em povos de terreiros, quilombos e comunidades negras rurais, e que esse grupo possui potencial produtivo baseado nos patrimônios imateriais e materiais, resguardados de forma a assegurar a ocupação territorial e a utilização dos recursos naturais locais. Reconhecendo que estes possuem princípios de autonomia e liberdade e detêm expressões culturais próprias e conhecimentos herdados de ancestrais, ligados às atividades produtivas.

A metodologia utilizada para o desenvolvimento do artigo é pesquisa exploratória com levantamento de dados primários e secundários, de natureza qualitativa com levantamento de dados através de entrevistas, análise observatória, análise documental e levantamento bibliográfico.

Revista Educação e Ciências Sociais (ISSN: 2595-9980), Salvador, v.2, n.2, 2019. 


\section{MARCOS LEGAIS DOS POVOS E COMUNIDADES TRADICIONAIS}

O Brasil e Estado da Bahia, com o objetivo de implementar políticas específicas para os segmentos de povos e comunidades tradicionais e população negra, instituíram alguns marcos políticos, como: A Lei 10.639/2003 que estabelece as diretrizes e bases da educação nacional, para incluir no currículo oficial da Rede de Ensino a obrigatoriedade da temática "História e Cultura Afro-Brasileira, a Lei 11.645/2008 que estabelece as diretrizes e bases da educação nacional, para incluir no currículo oficial da rede de ensino a obrigatoriedade da temática "História e Cultura Afro-Brasileira e Indígena"; Plano Nacional de Proteção à Liberdade Religiosa e de Promoção de Políticas Públicas para as Comunidades Tradicionais de Terreiro (2010); Frente Parlamentar em Defesa das Comunidades de Terreiros criada no Congresso Nacional (2011); Plano Nacional de Desenvolvimento Sustentável dos Povos e Comunidades Tradicionais de Matriz Africana (2013-2015); O Estatuto da Igualdade Racial e de Combate a Intolerância Religiosa, instituído através da Lei 13.182/2014, proposto para garantir à população negra a efetivação da igualdade de oportunidades, defesa de direitos individuais, coletivos e difusos e o combate à discriminação e demais formas de intolerância racial e religiosa; o Decreto 15.634/2014 - Política Estadual para o Desenvolvimento Sustentável dos Povos e Comunidades Tradicionais e o Plano Estadual de Desenvolvimento Sustentável dos Povos e Comunidades Tradicionais (2016) com o objetivo de fundamentar e orientar a implementação da Política Nacional para Povos e Comunidades Tradicionais, consiste no conjunto das ações de curto, médio e longo prazo para implementação dos princípios desta política; Lei 13.208/2014 que institui a Política Estadual de Fomento ao Empreendedorismo de Negros e Mulheres, fruto da necessidade de promover a inclusão produtiva, o desenvolvimento sustentável, com vistas ao maior empoderamento e autonomia dos Negros e Mulheres, num entendimento político de que esses públicos merecem ser alvo de Políticas Públicas pela sua formação histórica e exclusão social; o Decreto 16.320/2015 que institui a Década Estadual Afrodescendente, com o objetivo de promover maior conhecimento, valor e respeito às conquistas da população afrodescendente e às suas contribuições para a humanidade, além da erradicação da discriminação enfrentada, especialmente, pelos povos e comunidades tradicionais e a população afrodescendente.

Vale salientar que as ações públicas voltadas para o fomento das ações empreendedoras, com o objetivo de ampliar o aproveitamento de oportunidades é uma

Revista Educação e Ciências Sociais (ISSN: 2595-9980), Salvador, v.2, n.2, 2019. 
questão de promoção de igualdade e de desenvolvimento socioeconômico para a maioria da população brasileira, bem como para o desenvolvimento sustentável dos povos e comunidades tradicionais.

\section{O PROCESSO DE ENSINO E APRENDIZAGEM, ETNODESENVOLVIMENTO, EMPREENDEDORISMO E DESENVOLVIMENTO SUSTENTÁVEL.}

As técnicas pedagógicas, se considerarmos os desafios postos no âmbito da sociedade atual, tem um papel importante na construção e difusão do conhecimento para a população. Se pensarmos na Pedagogia Empreendedora, se faz necessário considerar os fenômenos da economia, o papel do ser humano na sociedade e novas tecnologias a partir da globalização. Dentro do processo formativo, esse conteúdo é mola fundamental para o desenvolvimento de práticas que considerem as habilidades pessoais, vivência na comunidade, experiências tradicionais transmitidas por gerações, gere inclusão social, emprego e renda e autonomia financeira. Esta pedagogia se propõe a contemplar uma metodologia de ensino de empreendedorismo objetivando vincular ações pedagógicas docentes e discentes com as tecnologias de desenvolvimento local, sustentável.

É fundamental ressaltar a importância dos conceitos de Etnodesenvolvimento para reforçar o fortalecimento da questão étnica para a pesquisa em questão.

Para Stavenhagen (1984:57), citado por Azanha (2002), o

Etnodesenvolvimento seria o desenvolvimento que mantém o diferencial sociocultural de uma sociedade, ou seja, sua etnicidade. Nessa acepção, desenvolvimento tem pouco ou nada a ver com indicadores de 'progresso' no sentido usual do termo: [...] $\mathrm{Na}$ definição de Stavenhagen, 'o etnodesenvolvimento significa que uma etnia, autóctone, tribal ou outra, detém o controle sobre suas próprias terras, seus recursos, sua organização social e sua cultura, e é livre para negociar com o Estado o estabelecimento de relações segundo seus interesses' (AZANHA, 2002, p. 31).

Vale ressaltar que pensar na perspectiva do Etnodesenvolvimento é considerar as especificidades do objeto da pesquisa e aspectos como, políticas públicas, fatores econômicos, e culturais. Pressupõe a transformação dos povos tradicionais no que tange autonomia, considerando a manutenção de troca de saberes tradicionais, capacitação técnica 
dos grupos étnicos, relação equilibrada com o meio ambiente e preservação de aspectos culturais que salvaguardam os patrimônios materiais e imateriais.

Ao refletirmos sobre a proposta do Etnodesenvolvimento, pode-se afirmar que o processo, tem a intenção de manter e transformar os grupos étnicos em aspectos ligados à produtividade autônoma, que perpassam por experiências históricas, saberes tradicionais de um grupo culturalmente diferenciado, para que esse grupo consiga autonomia e gerencie seus próprios negócios.

Esses grupos possuem um potencial para impulsionar redes de negócios que reforcem a capacidade de articulação, conhecimentos e habilidades para transformar realidades, a partir de trocas que consideram as especificidades e competências. A integração desses elementos perpassa pela construção através de formações que valorizem aspectos socioculturais, formas de vida e de organização.

No processo de formação através do sistema educacional, está previsto no artigo 22 da Lei 9.394/1996 - Lei de Diretrizes e Bases da Educação Nacional que a educação básica tem por finalidade desenvolver o educando, assegurar-lhe a formação comum indispensável para o exercício da cidadania e fornecer-lhe meios para progredir no trabalho e em estudos posteriores [...] (BRASIL, 1996). Mas, não há preocupação em formar pessoas com padrão mental diferenciado, conforme afirma Dolabela (2008 p. 61), [...] a escola consegue realmente é inibir a capacidade empreendedora. A importância de abordar o tema empreendedorismo no âmbito da educação é a possibilidade de transformar vidas. Já para Stockmanns (2015), “[...] quando uma população tem perfil empreendedor, maior a possibilidade daquela sociedade se desenvolver economicamente e produzir maior potencial de riquezas".

Cabe salientar, que o ser humano precisa de uma motivação para atuar de forma transformadora e como consequência proporcionar a autonomia econômica. Pois, conforme Dolabela (2003),

as condições para ser empreendedor estão ligadas ao ambiente macro, à democracia, à cooperação e à estrutura de poder. Ser empreendedor também requer um conhecimento de um caminho bem complexo que imaginam e que demanda uma visão bem ampla das causas e das consequências dos fatores que vivenciam. [...] (DOLABELA, 2003). 
Para desenvolver os grupos produtivos, do ponto de vista de uma perspectiva diferenciada de fortalecimento das suas habilidades e a capacidade de mudar a realidade proporcionando autonomia é despertar nestas comunidades a possibilidade através da educação. Segundo Dolabela (2003),

[...] A tarefa da educação empreendedora é principalmente fortalecer os valores empreendedores na sociedade. É dar sinalização positiva para a capacidade individual e coletiva de gerar valores para toda a comunidade, a capacidade de inovar, de ser autônomo, de buscar a sustentabilidade, de ser protagonista. [...] (DOLABELA, 2003, p. 103).

Para a construção desta pesquisa, empregar fundamentos teóricos de educação empreendedora e a pedagogia social como teoria da educação que exprime a prática abordando experiências, teorias e práticas são essenciais para o objeto de estudo proposto pela pesquisadora. Freire (1967) citado por Gadotti (2012) caracteriza pedagogia social como um projeto de transformação política e social visando ao fim da exclusão e da desigualdade, voltada, portanto, para as classes populares.

A educação social é a prática das bases teóricas e metodológicas da pedagogia social. Esta educação tem sido realizada em Organizações Não Governamentais (ONGs), Organizações da Sociedade Civil (OSCs) e nos movimentos sociais e populares, pois estas buscam direito a educação através da mobilização das comunidades. A pesquisa perpassa pelo caráter educativo das práticas de educação no campo social, em razão disso, trazer o conceito de educação comunitária favorecerá no enquadramento da temática, visto que, segundo Gadotti (2012) há conotações diferentes entre a educação popular, educação social e educação comunitária, ainda que as três tenham afinidades ideológicas, pois este autor aborda a educação comunitária como concepção de desenvolvimento de comunidades, contribuindo com a organização e o fortalecimento dos laços de solidariedade entre populações empobrecidas e discriminadas.

O processo de ensino tem como principais atores o professor e o aluno, este dois atores em atividade gera a transmissão de conteúdo que será transformado em conhecimento após a assimilação do que está sendo transmitido. Segundo Libâneo (1994, p. 90 apud FREITAS, 2016, p. 02) "a relação entre ensino e aprendizagem não é mecânica, não é uma simples transmissão do professor que ensina para um aluno que aprende". Existe uma relação reciproca, que gera um impulsionamento no processo de ensino e aprendizagem. 
Estes conceitos favorecem no perfil do objeto de estudo em questão, pois há uma preocupação na transmissão de conteúdos de geração para geração baseadas numa visão sistêmica e que integram conhecimentos botânicos, medicinais, gastronômico, que contribui para a ampliação na perspectiva de conservar os recursos naturais e fortalecimento da produção familiar.

O empreendedorismo é a capacidade de identificar uma oportunidade, a partir da resolução de um problema e transformá-la em negócio de sucesso. Empreendedorismo é uma palavra derivada do inglês entrepreneursbip, e originada da palavra francesa entrepreuneur que, segundo Dornelas (2001), significa aquele que assume riscos e começa algo novo. E o mesmo autor nos descreve que, na Idade Média, empreendedor era a pessoa que gerenciava projetos de produção, utilizando os recursos disponíveis.

No entanto, até então, os principais processos de ensino voltados para empreendedorismo se orientaram de modo privilegiado para a criação de empresas e novos negócios, deixando à margem um processo mais inclusivo de formação que privilegie a criatividade, as redes organizadas de povos tradicionais, a abordagem e solução de problemas por grupos produtivos.

\section{PERFIL DOS EMPREENDEDORES}

A Cooperativa de Etnodesenvolvimento Kitaanda Bantu localiza-se no município de Cachoeira, no Território de Identidade Recôncavo. O Recôncavo Baiano, considerando a divisão espacial, área geográfica que fica ao redor da Baia de Todos os Santos, possui 576,6 mil habitantes (IBGE, 2010), atualmente, composto por 20 (vinte) municípios. O nome é fruto da parte côncava do litoral da Bahia e do formato côncavo da região. O Recôncavo também foi núcleo regional, com papel importante no projeto de colonização do Brasil e Cachoeira já foi sede do governo duas vezes, uma vez durante as lutas pela Independência da Bahia e da segunda foi durante a Revolta da Sabinada, em 1837. Com área territorial de aproximadamente $6.500 \mathrm{~km}^{2}$, o Recôncavo é um dos berços da cultura baiana e possui muitos patrimônios materiais e imateriais, que conforme o artigo 216 da Constituição Federal configura patrimônio "as formas de expressão; os modos de criar; as criações científicas, artísticas e tecnológicas; as obras, objetos, documentos, edificações e demais espaços destinados às manifestações artístico-culturais; além de conjuntos urbanos e sítios 
de valor histórico, paisagístico, artístico, arqueológico, paleontológico, ecológico e científico".

Em Cachoeira, segundo dados do Mapeamento dos Espaços de Religiões de Matrizes Africanas do Recôncavo (2012), é o município que possui 48 (quarenta e oito) terreiros das religiões de matriz africana e 16 (dezesseis) comunidades quilombolas reconhecidas pela Fundação Cultural Palmares, Caonge, Dendê, Engenho da Ponte, Engenho da Praia, Kalemba, Caimbongo, Calolé, Imbiara, Tombo, Engenho da Vitória, Brejo do Engenho da Guaíba, Engenho da Cruz, Tabuleiro da Vitória, Engenho Novo do Vale do Iguape, São Francisco do Paraguaçu, São Tiago do Iguape.

O território Metropolitano de Salvador é composto por 13 (treze) municípios, com 3.899.533 de população residente (IBGE, 2017). Esse território concentra a maior receita, maior concentração de renda e de miséria. Embora possua cerca de $25 \%$ da população do estado, acumula mais de $40 \%$ do PIB oriundo da atividade industrial 60;7\%, serviço, comércio e turismo 39,1\% e agropecuária 0,2\% (PTDS, 2010). Estes percentuais expressam uma invisibilidade e quase que a inexistência da agricultura familiar no território, mas existe um quantitativo representativo de agricultura familiar, urbana e Peri urbana, com a presença de Comunidades Rurais, Quilombolas, Povos de Terreiros de Candomblé e Indígenas, Assentamentos de Reforma Agrária, além de Pescadores e Marisqueiras, Ciganos e Extrativistas.

Os 20 (vinte) cooperados ficam localizados nos territórios de identidade Recôncavo e Região Metropolitana de Salvador, nos municípios de Cachoeira, Camaçari, São Francisco do Conde e Salvador, mas os núcleos produtivos abrangem mais dois territórios, Sertão do São Francisco e Litoral Sul. O público atendido pela rede é de 16 a 70 anos, há uma predominância de mulheres, no quesito raça/cor há $92 \%$ de negros e negras e $8 \%$ de indígenas. Os empreendedores atuam com Agricultura Familiar Agroecológica e Orgânica, Gastronomia Afro - Alimentação, Extrativismo, Confecção, Artesanato e Formação Cultural. Os empreendedores consideram a Cooperativa Kitaanda Bantu como uma estratégia de empreendedorismo de povos e comunidades tradicionais. A gestão da cooperativa utiliza estratégia de formação continuada e o processo de ensino e aprendizagem ocorre com o compartilhamento de conhecimentos entre os participantes e com a interação com técnicos contratados ou de entidades parceiras. Os conteúdos que já foram abordados nas formações dos membros foram: Oficinas sobre os patrimônios culturais das 
comunidades; Oficinas sobre o Patrimônio Cultural Linguístico Bantu; Oficinas com foco em gestão administrativa e financeira; Oficinas com foco em gestão comercial; Oficinas com foco em gestão estratégica e sustentabilidade; Intercâmbios culturais e troca de experiências; Eco intercâmbios; Oficinas de saberes e fazeres tradicionais: bordado, culinária, artesanato, plantas medicinais, habilidades tradicionais e Oficinas sobre finanças solidárias. A Cooperativa realiza grandes esforços para sua manutenção, produção e comercialização de produtos, dessa forma, a sistematização dos aprendizados adquiridos pelos membros da Kitaanda Bantu ainda não ocorreu.

A perspectiva da Cooperativa para o ano de 2019/2020 é a finalização da formalização da cooperativa e sua entrada em redes e fóruns específicos; apoiar as mulheres participantes com oficinas envolvendo temáticas específicas e autoestima; acessar programas de crédito para agricultura familiar, editais de economia solidária; fortalecer a dinâmica de produção bem como, a inserção dos produtos em outros estados; conquistar alvarás e licenças para a comercialização de produtos para os quais são exigidos; acessar o Programa Nacional de Alimentação Escolar - PNAE e outros programas de compras institucionais.

\section{DADOS DA PESQUISA}

A metodologia utilizada para o desenvolvimento do artigo é pesquisa exploratória com levantamento de dados primários e secundários, de natureza qualitativa com levantamento de dados através de entrevistas, análise observatória, análise documental e levantamento bibliográfico.

A coleta de dados foi realizada em duas etapas: a primeira com a Coordenadora Geral da Cooperativa, destacando informações gerais do perfil dos empreendedores e a segunda etapa uma entrevista direcionada com 06 (seis) empreendedoras que constituem a Cooperativa, a seleção das empreendedoras foi realizada pelo critério de acesso durante o período de execução desta pesquisa. Além do levantamento bibliográfico, através de fontes secundárias: livros, artigos e planos, e também análise observatória e documental.

As empreendedoras entrevistadas estão na faixa etária de 30 a 65 anos, estão distribuídas entre os segmentos de povos e comunidades tradicionais, 03 (três) são de Terreiro de Nação Angola, 02 (duas) de Terreiro de Nação Ketu e uma é oriunda de

Revista Educação e Ciências Sociais (ISSN: 2595-9980), Salvador, v.2, n.2, 2019. 
comunidade negra rural. O segmento produtivo destas é composto por empreendimentos que produzem artesanato, horta comunitária, gastronomia, extrativismo, confecções e medicina fitoterápica. Estão localizadas nos territórios de identidade, Metropolitano de Salvador e Recôncavo, nos municípios de Salvador, São Francisco do Conde, Santo Amaro e Cachoeira.

Quanto ao fator escolaridade, a maioria possui ensino médio e uma entrevistada possui educação superior e a outra analfabeta. Todas as entrevistadas informaram que já participaram de oficinas propostas pela Cooperativa de Etnodesenvolvimento Kitaanda Bantu, como temáticas diversas: Associativismo e Cooperativismo, Etnodesenvolvimento, Oficina de Gastronomia, Oficina de Gestão Comunitária, Oficina de Patrimônio Cultural e Etnodesenvolvimento e Oficina Dandara Kodya MBote. Todas as formações foram ministradas por membros da Associação Nacional de Preservação do Patrimônio Bantu ACBANTU e o método utilizado foi expositivo e houve a divisão da carga horária entre teoria e prática. O material didático utilizado para as oficinas são apostilas.

As mulheres entrevistadas abordam que as formações foram importantes, pois as temáticas escolhidas foram construídas coletivamente com o grupo, por razão da demanda latente dos grupos. Pontuaram que a metodologia utilizada nas oficinas favoreceu o processo de ensino e aprendizagem e puderam participar da etapa de mobilização e este fator favoreceu no entrosamento das mobilizadoras com as pessoas da comunidade. Na pesquisa aplicada surgiram temáticas transversais como valorização da mulher, inclusão da juventude nas formações promovidas pela Cooperativa, liderança colaborativa, além das oficinas promoverem mudanças na gestão, aprendizagem específica na manipulação de alimentos e gestão do produto.

Ao abordarmos a relação que as cooperadas possuem com o empreendedorismo, todas elas valorizam as suas habilidades e relatam que são empreendedoras em mais de um segmento produtivo. Algumas relatam que aprenderam com a geração anterior, e pode-se observar o aprendizado obtido, no qual elas sentem orgulho de reforçar e dar continuidade a esses saberes. Uma empreendedora relatou que já teve experiência com outros empreendimentos e atualmente ajuda outras mulheres a se descobrirem e crescerem profissionalmente. 
As mulheres entrevistadas informaram que têm interesse em participar de outras formações que a Cooperativa proporcionar, pois avaliam que é importante o fortalecimento da participação delas na cooperativa e nas feiras que esta realiza. Ao questionarmos sobre a comunicação utilizada pela Cooperativa foi relatado que o principal meio de comunicação é o aplicativo de celular WhatsApp.

Observa-se que as empreendedoras têm uma perspectiva positiva para os projetos futuros da Cooperativa, pois discorrem que a Cooperativa possibilita o crescimento delas e o fortalecimento das comunidades. Almejam "que todos os núcleos produtivos possam aproveitar as oportunidades de ampliar suas redes de atuação e fortalecer a produção do terreiro." E relatam que gostariam que a Kitaanda Bantu se fortaleça e possa ajudar a desenvolver novos projetos, além de abordarem a perspectiva de mais visibilidade e vendas para que não tenham que repassar mercadorias para "atravessadores", que são muito comuns nos segmentos de extrativistas e nos empreendimentos de hortas comunitárias.

Na fase de análise observatória a pesquisadora participou do evento de Lançamento do projeto Sala Ia Njila - O caminho do Trabalho, fruto do edital 001/2018 proposto pela Secretaria de Promoção de Igualdade Racial do Estado da Bahia e acompanhou outras feiras através do Projeto Nkaanda: Feira Agroecológica no Pelourinho. O projeto se propôs "consolidar a Rede Nkaanda de Etnoempreendimentos de Agricultura Familiar e Economia Solidária de Povos e Comunidades Tradicionais e Comunidades Negras Rurais com vistas a preservar seus patrimônios culturais, expandir suas atividades, aprimorar as condições de trabalho, proporcionar a ampliação de renda, melhorar a qualidade dos alimentos e artesanatos produzidos viabilizando o sucesso dos empreendimentos aos canais de comercialização, públicos e privados, tornando-se instrumentos importantes de inclusão produtiva no contexto do Eixo Desenvolvimento da Década Estadual de Afrodescendente da Bahia". Neste evento, ocorreu uma roda de diálogos, na qual a coordenadora, Ana Paula Lima, abordou o objetivo do projeto dando as boas-vindas aos empreendedores e informou das atividades propostas no projeto: mapeamento dos núcleos produtivos, estudos de viabilidade financeira, formação com a temática da Década Afrodescendente - Eixo Desenvolvimento, Exposições e Roda de diálogos nos territórios Recôncavo e Sertão do São Francisco. Os representantes do Poder Público que estavam presentes abordaram a importância da realização da feira envolvendo esse público alvo proposto pela entidade e a maioria reforçou a parceria estabelecida com a entidade para a realização do projeto. A Coordenadora Geral da Cooperativa de Etnodesenvolvimento Kitaanda Bantu, também 
abordou sobre as estratégias coletivas para comercialização dos grupos produtivos presentes na feira e a importância da iniciativa do projeto em estimular a geração de trabalho e renda a partir dos valores ancestrais e foi possível observar como a entidade está articulada enquanto rede para integrar ações conjuntas com comunidades de vários territórios que fazem parte do núcleo produtivo e com parceiros do Poder Público para viabilizar as atividades que têm a proposta de visibilizar e promover a comercialização de produtos dos povos e comunidades tradicionais. Ocorreram formações voltadas gestão administrativa, comercial e financeira, Patrimônio Cultural Linguístico Bantu e Oficinas com foco em gestão estratégica e sustentabilidade. Pode-se constatar que a Cooperativa estimula e articula muitas formações voltadas para Empreendedorismo e outras temáticas, em parceria com Centros Públicos de Economia Solidária, entidades parceiras, secretarias do Governo de Estado e pelo Programa Regional de Desenvolvimento do Turismo - PRODETUR.

Foi possível observar que o processo de ensino e aprendizagem se dá com o compartilhamento de conhecimentos entre os participantes e com a interação com técnicos contratados, de entidades parceiras ou membros da ACBANTU. O perfil de empreendedoras entrevistadas e a análise observatória demonstra o empenho das pessoas na produção e comercialização dos produtos, mas a gestão estratégica está sob responsabilidade da gestora da cooperativa. Os saberes tradicionais e ancestrais de cada empreendedora são compartilhados e vivenciados no coletivo, possibilitando trocas. Nota-se que esta educação não formal é significativa, contextualizada e emancipadora, pois promove a este grupo o desenvolvimento de potencialidades.

De acordo com os conteúdos que foram coletados na pesquisa, a análise observatória e documental é possível perceber que há uma perspectiva de futuro próspero para a Cooperativa de Etnodesenvolvimento Kitaanda Bantu, pois o aprendizado continuado e o comprometimento das partes favorecem a ação integrada (poder público, núcleos produtivos e cooperados) que já está consolidada na dinâmica da cooperativa.

\section{ANÁLISE DA PESQUISA}

A Cooperativa de Etnodesenvolvimento Kitaanda Bantu possui em sua maioria mulheres, com faixa etária acima de 65 anos se concentra um total de $82 \%$ destas. A cooperativa contempla os segmentos de povos e comunidades tradicionais: povos de terreiros e indígenas, e comunidades quilombolas, marisqueiras e pescadores.

Revista Educação e Ciências Sociais (ISSN: 2595-9980), Salvador, v.2, n.2, 2019. 
Pode-se constatar que a Cooperativa estimula e articula muitas formações voltadas para Empreendedorismo e outras temáticas, em parceria com Centros Públicos de Economia Solidária, entidades parceiras, secretarias do Governo de Estado e pelo Programa Regional de Desenvolvimento do Turismo - PRODETUR. Ocorreram formações como: Oficinas sobre os patrimônios culturais das comunidades; Oficinas sobre o Patrimônio Cultural Linguístico Bantu; Oficinas com foco em gestão administrativa e financeira; Oficinas com foco em gestão comercial; Oficinas com foco em gestão estratégica e sustentabilidade; Intercâmbios culturais e troca de experiências; Eco intercâmbios; Oficinas de saberes e fazeres tradicionais: bordado, culinária, artesanato, plantas medicinais, habilidades tradicionais; Oficinas sobre finanças solidárias. E foi possível observar que o processo de ensino e aprendizagem se dá com o compartilhamento de conhecimentos entre os participantes e com a interação com técnicos contratados, de entidades parceiras ou membros da ACBANTU.

O perfil de empreendedoras entrevistadas e a análise observatória demonstra o empenho das pessoas na produção e comercialização dos produtos, no entanto o papel de gestão estratégica concentra-se na gestora da cooperativa. Os saberes tradicionais e ancestrais de cada empreendedora são compartilhados e vivenciados no coletivo, possibilitando trocas. Nota-se que esta educação não formal é significativa, contextualizada e emancipadora, pois promove a este grupo o desenvolvimento de potencialidades.

Sendo questionadas sobre a relação entre as cooperadas e o empreendedorismo, foi revelado que a cooperativa é uma estratégia de empreendedorismo de povos e comunidades tradicionais. O empreendedorismo de povos e comunidades tradicionais possui um diferencial, pois este atua com integração dos elementos civilizatórios de grupos étnicos, como mecanismo de sustentabilidade protagonista dessas comunidades e este está relacionada ao desenvolvimento econômico e material, usando os recursos naturais de forma inteligente e promovendo o desenvolvimento local. As iniciativas promovem inclusão social, construção coletiva, resgate da memória, preservação da identidade e fortalecimento da economia local.

Os resultados confirmam que o processo de ensino e aprendizagem descrito na pesquisa foi dialógico, conforme conceito abordado por Freire (2003), composto de vivências, histórias e individualidades e trocas de experiências, que foram sempre 
demonstradas no decorrer da pesquisa, quando se tratou das formações transmitidas para os cooperados.

Analisando os dados coletados sobre a comunicação foi possível observar que a comunicação interna é feita por meio de aplicativo de celular WhatsApp, que favorece a troca de informações, pois os cooperados e os núcleos ficam geograficamente distantes e a comunicação institucional utiliza ferramentas digitais (site, redes sociais) e peças impressas (folders e folhetos). Esta comunicação necessita de planejamento de comunicação específico para a Cooperativa, pois como a cooperativa está em fase de registro legal, toda a comunicação é feita vinculada a ACBANTU que aborda conteúdos de outros projetos como: Rede Kôdya e Ponto de Cultura.

De acordo com os conteúdos que foram coletados na pesquisa, a análise observatória e documental é possível perceber que há uma perspectiva de futuro próspero para a Cooperativa de Etnodesenvolvimento Kitaanda Bantu, pois o aprendizado continuado e o comprometimento das partes favorecem a ação integrada (poder público, núcleos produtivos e cooperados) que já está consolidada na dinâmica da cooperativa.

\section{CONSIDERAÇÕES FINAIS}

Conforme o estudo realizado neste artigo, foi possível destacar que a proposta da Cooperativa de Etnodesenvolvimento Kitaanda Bantu está alinhada com o público atendido e observa-se que há um anseio de promover o rompimento das práticas excludentes, reflexo da desigualdade racial e uma construção de novas perspectivas a partir das formações, favorecendo assim o processo de ensino e aprendizagem dos cooperados. Ao descrever o processo de ensino e aprendizagem dos empreendedores da Cooperativa de Etnodesenvolvimento Kitaanda Bantu a pesquisadora pode observar que há um esforço da instituição em promover formações para os cooperados, mas há a necessidade de integrar um processo experimental e reflexivo, no qual os cooperados possam também contribuir para o desenvolvimento de uma proposta. $O$ processo de aprendizagem experimental torna-se importante para incentivar o processo criativo baseado numa análise do contexto que permite identificar e propor soluções de problemas que ocorrem no cotidiano de cada empreendedor e que contribua com a gestão da cooperativa. Os conteúdos das formações

Revista Educação e Ciências Sociais (ISSN: 2595-9980), Salvador, v.2, n.2, 2019. 
coletados pela pesquisa são de suma importância para a cooperativa e para os empreendedores, mas ressaltam-se a necessidade de melhor sistematização dos conteúdos e propostas para que na prática seja mais efetiva a aplicação dos conhecimentos, pois a pesquisa observatória de campo proporcionou a identificação das dificuldades existentes por parte dos empreendedores.

O dado positivo também coletado através da pesquisa são as parcerias celebradas com órgãos governamentais, que demonstra o aproveitamento da política pública prevista, conforme estabelecido no inciso I, do artigo $5^{\circ}$ do Estatuto de Igualdade Racial da Bahia que adota como diretrizes político-jurídicas para projetos de desenvolvimento, políticas públicas e medidas de ação afirmativa, a inclusão do segmento da população atingido pela desigualdade racial e a promoção da igualdade racial, na dimensão reparatória e compensatória para os descendentes das vítimas da escravidão, do racismo e das demais práticas institucionais e sociais históricas que contribuíram para as profundas desigualdades raciais e as persistentes práticas de discriminação racial na sociedade baiana, inclusive em face dos povos de terreiros de religiões afro-brasileiras, mesmo observando que as ações governamentais ainda são incipientes, diante do processo reparatório de mais de 350 anos de escravização, considerando aproximadamente 130 anos de uma abolição inacabada, pois as relações de subordinação sócio raciais brasileiras continuam até os dias atuais.

Há evidências que o empreendedorismo está inerente aos grupos produtivos em questão, pois em algum momento na vida destes, não existia o termo empreendedorismo que está tão em voga nos dias atuais, porém a pesquisa proporcionou observar que as mulheres empreendiam por sobrevivência. E o novo processo de organizações em rede proporciona mobilização, fortalecimento do mercado, circulação de moeda, redução de riscos sociais, aquecimento econômico, fortalecimento da cidadania e autoestima, intercâmbios de produtos e saberes, valorização e reconhecimento dos saberes tradicionais de cada comunidade e oportunidades de mecanismos de sustentabilidade.

Este trabalho poderá ter um impacto importante sobre o desenvolvimento das práticas, contribuindo para melhoria no processo de fortalecimento do empreendedorismo na Cooperativa de Etnodesenvolvimento Kitaanda Bantu, pois a hipótese da perspectiva do empreendedorismo fortalecer o potencial produtivo da cooperativa foi ratificada, tendo em vista que o impulsionamento desses empreendedores somado aos esforços da gestão da cooperativa poderá fortalecer a dinâmica de produção bem como, a inserção dos produtos

Revista Educação e Ciências Sociais (ISSN: 2595-9980), Salvador, v.2, n.2, 2019. 
em outros estados, conquista de licenças para a comercialização de produtos, acessar novos programas de crédito e outros editais, que são perspectivas que a própria gestão relatou na pesquisa.

A pesquisa possibilitou a análise de que o processo de ensino e aprendizagem tornase um alicerce para o fortalecimento do segmento marcado por invisibilidade e que necessita de levantamentos de dados para a construção de políticas públicas que agreguem a relação educação, gestão e desenvolvimento, além de gerar mobilização de atores sociais, novos processos de gestão em rede para sustentabilidade dos projetos e desenvolvimento local sustentável, ações inovadoras, agregados aos saberes tradicionais, fundamentados a partir do modo de vida dos povos e comunidades tradicionais.

\section{REFERÊNCIAS}

BAHIA, Decreto 15.634 de 06 de Novembro de 2014. Política Estadual para o desenvolvimento sustentável dos povos e comunidades tradicionais. Diário Oficial da Bahia.

BAHIA, Lei 13.182. Estatuto de Igualdade Racial e de Combate à intolerância religiosa, 2014. Diário Oficial da Bahia.

BAHIA, Decreto 16.320 de 21 de Setembro de 2015. Década Estadual Afrodescendente. Diário Oficial da Bahia.

BAHIA, Lei 13.208. Política de Fomento ao Empreendedorismo de Negros e Mulheres, 2014.

\section{BAHIA, Plano Estadual de Desenvolvimento Sustentável dos Povos e Comunidades} Tradicionais, 2016.

BRASIL, Decreto 6.040 de 07 de fevereiro de 2007, Política Nacional de Desenvolvimento Sustentável dos Povos e Comunidades Tradicionais. Diário Oficial da República Federativa do Brasil.

BRASIL. IBGE. Panorama Cidades 2010. Disponível em

https://cidades.ibge.gov.br/brasil/ba/cachoeira/panorama>. Acesso em 08 de abril de 2019.

BRASIL. IBGE. Panorama Cidades 2017. Disponível em

https://cidades.ibge.gov.br/brasil/ba/salvador/panorama>. Acesso em 08 de abril de 2019.

BRASIL, Lei 10.639, de 9 de janeiro de 2003. Disponível em:

http://www.planalto.gov.br/CCivil_03/leis/2003/L10.639.htm. Acesso em: 20 mar. 2019.

Revista Educação e Ciências Sociais (ISSN: 2595-9980), Salvador, v.2, n.2, 2019. 
BRASIL. Lei 11.645, de 10 de marco de 2008. Disponível em: http://www.planalto.gov.br/ccivil_03/_ato2007-2010/2008/lei/111645.htm Acesso em: 20 mar. 2019.

BRASIL, Lei 9.394 de dezembro de 1996. Estabelece a Lei de diretrizes e Bases da Educação Nacional. 5. ed. Brasília, DF: Câmara dos Deputados, 2010.

BRASIL, Plano Nacional de Desenvolvimento Sustentável dos Povos e Comunidades Tradicionais de Matriz Africana (2013-2015).

CUNHA, L. A. Educação, estado e democracia no Brasil. São Paulo: Cortez, 1991.

DOLABELA, Fernando. O segredo de Luísa. São Paulo: Cultura Editores Associados, 1999.

DOLABELA, Fernando. Pedagogia empreendedora. São Paulo: Editora Cultura, 2003.

DOLABELA, Fernando. Oficina do empreendedor: a metodologia de ensino que ajuda a transformar conhecimento em riqueza. Rio de Janeiro: Sextante, 2008.

FREIRE, Paulo. Pedagogia do oprimido. 49. ed. Rio de Janeiro: Paz e Terra, 2005.

GADOTTI, Moacir. Educar para um outro mundo possível. São Paulo: Publisher, 2007.

GADOTTI, Moacir. EDUCAÇÃO POPULAR, EDUCAÇÃO SOCIAL, EDUCAÇÃO

COMUNITÁRIA - Conceitos e práticas diversas, cimentadas por uma causa comum, 2012.

Mapeamento dos Espaços de Religiões de Matrizes Africanas do Recôncavo. Sepromi. Editora: EGBA, 2012.

OTTO, Hans-Uwe. Origens da Pedagogia Social. In SOUZA NETO, João Clemente; SILVA, Roberto da; MOURA, Rogério (Orgs.). Pedagogia Social. São Paulo Expressão e Arte Editora, 2009.

QUIJANO, Aníbal. A América Latina Sobreviverá? Revista São Paulo em Perspectiva. São Paulo, v.7, n.2, 1993, pp. 60-66.

SCHWARCZ , Lilia M. , GOMES, Flávio (orgs.). Dicionário da escravidão e liberdade: 50 textos críticos. São Paulo: Companhia das Letras, 2018.

SITE ACBANTU. Disponível em: http://www.acbantu.org.br/. Acesso em: 08 abr. 2019.

STOCKMANNS, Jussara Isabel. Pedagogia empreendedora. Paraná: Gráfica Unicentro, 2015 .

TRILLA, Jaume e Elie Ghanem, 2008. Educação formal e não-formal: pontos e contrapontos. São Paulo: Summus. 